\title{
Liraglutide Versus Lixisenatide: Long-Term Cost- Effectiveness of GLP-1 Receptor Agonist Therapy for the Treatment of Type 2 Diabetes in Spain
}

\author{
Pedro Mezquita-Raya • Antonio Ramírez de Arellano · Nana Kragh • \\ Gabriela Vega-Hernandez · Johannes Pöhlmann · William J. Valentine • \\ Barnaby Hunt $\mathbb{D}$
}

Received: December 22, 2016 / Published online: February 21, 2017

(c) The Author(s) 2017. This article is published with open access at Springerlink.com

\begin{abstract}
Introduction: Glucagon-like peptide-1 (GLP-1) receptor agonists are used successfully in the treatment of patients with type 2 diabetes as they are associated with low hypoglycemia rates, weight loss and improved glycemic control. This study compared, in the Spanish setting, the cost-effectiveness of liraglutide $1.8 \mathrm{mg}$ versus lixisenatide $20 \mu \mathrm{g}$, both GLP-1 receptor agonists, for patients with type 2 diabetes who had not achieved glycemic control targets on metformin monotherapy.

Methods: The IMS CORE Diabetes Model was used to project clinical outcomes and costs,
\end{abstract}

Enhanced content To view enhanced content for this article go to http://www.medengine.com/Redeem/ 0D87F06002422E63.

P. Mezquita-Raya

Unidad de Endocrinología y Nutrición, Hospital

Torrecárdenas, Almería, Spain

A. Ramírez de Arellano

Novo Nordisk Pharma S.A., Madrid, Spain

N. Kragh

Novo Nordisk A/S, Søborg, Denmark

G. Vega-Hernandez

Novo Nordisk Ltd, Gatwick, UK

J. Pöhlmann · W. J. Valentine · B. Hunt ( $₫)$

Ossian Health Economics and Communications,

Basel, Switzerland

e-mail: hunt@ossianconsulting.com expressed in 2015 Euros, over patient lifetimes. Baseline cohort data and treatment effects were taken from the 26-week, open-label LIRA-LIXI ${ }^{\mathrm{TM}}$ trial (NCT01973231). Treatment and management costs of diabetes-related complications were retrieved from published sources and databases. Future benefits and costs were discounted by $3 \%$ annually. Sensitivity analyses were conducted.

\section{Results:}

Compared with lixisenatide $20 \mu$ g, liraglutide $1.8 \mathrm{mg}$ was associated with higher life expectancy (14.42 vs. 14.29 years), higher quality-adjusted life expectancy [9.40 versus 9.26 quality-adjusted life years (QALYs)] and a reduced incidence of diabetes-related complications. Higher acquisition costs resulted in higher total costs for liraglutide $1.8 \mathrm{mg}$ (EUR 42,689) than for lixisenatide $20 \mu \mathrm{g}$ (EUR 42,143), but these were partly offset by reduced costs of treating diabetes-related complications (EUR 29,613 vs. EUR 30,636). Projected clinical outcomes and costs resulted in an incremental cost-effectiveness ratio of EUR 4113 per QALY gained for liraglutide $1.8 \mathrm{mg}$ versus lixisenatide $20 \mu \mathrm{g}$.

Conclusions: Long-term projections in the Spanish setting suggest that liraglutide $1.8 \mathrm{mg}$ is likely to be cost-effective compared with lixisenatide $20 \mu \mathrm{g}$ in type 2 diabetes patients who have not achieved glycemic control targets on metformin monotherapy. Liraglutide $1.8 \mathrm{mg}$ presents a clinically and economically attractive treatment option in the Spanish setting. 
Keywords: Cost; Cost-effectiveness; Diabetes mellitus; Liraglutide; Lixisenatide; Spain

\section{INTRODUCTION}

The International Diabetes Federation estimated the prevalence of diabetes mellitus in Spain to be approximately $10.4 \%$, with around 3.6 million adults diagnosed with diabetes and 1.3 million undiagnosed in 2015 [1]. The disease is a considerable burden on Spanish patients and, in 2015, diabetes mellitus was ranked eighth among causes for disability-adjusted life-years in Spain [2]. Patients with diabetes are often affected by multiple morbidities, including foot ulcer, cardiovascular disease or renal failure [3-5]. Diabetes also causes considerable costs to the Spanish Healthcare System and economy. In 2009 , diabetes-related costs accounted for $8 \%$ of all healthcare system expenditures, with EUR 5.1 billion in direct costs and EUR 2.8 billion in lost labor productivity [6]. A study in the Catalonia region estimated that, in 2011, annual direct medical costs for a patient with type 2 diabetes were EUR 3110, compared with EUR 1803 for a patient without diabetes [7]. Extrapolating these results to all of Spain and assuming a prevalence of $7.8 \%$, the authors estimated yearly direct costs of type 2 diabetes to be around EUR 10 billion.

The clinical and economic burden imposed by diabetes can be reduced if patients are treated effectively, i.e. if they meet glycemic targets to reduce the risk of micro- and macrovascular complications [8-10]. In line with other guidelines, Spanish treatment guidelines recommend glycated hemoglobin (HbA1c) target levels of $<6.5 \%(47.5 \mathrm{mmol} / \mathrm{mol})$ if patients are newly diagnosed with type 2 diabetes, younger than 70 years and without diabetes-related complications, and $<7.5 \% \quad(58.5 \mathrm{mmol} / \mathrm{mol})$ otherwise [11]. However, only 32 and $68 \%$ of Spanish patients are reaching HbA1c levels of $<6.5 \% \quad(47.5 \mathrm{mmol} / \mathrm{mol}) \quad$ and $\quad<7.5 \%$ $(58.5 \mathrm{mmol} / \mathrm{mol})$, respectively, and only $55 \%$ of patients are adequately controlled with respect to individualized glycemic targets [12]. In Catalonia, between 2007 and 2013 the percentages of patients who reached an HbA1c value of $\leq 7 \%$ ( $53 \mathrm{mmol} / \mathrm{mol}$ ) ranged between 52 and $56 \%$ but did not notably increase over time [13].

The Spanish Diabetes Society recommends the use of metformin as the first-line pharmaceutical therapy for patients with type 2 diabetes and an HbA1c level of $\leq 8.5 \%$ $(69.4 \mathrm{mmol} / \mathrm{mol})$ [11]. If treatment targets are not met within 3 months, second-line treatments should be added. Glucagon-like peptide-1 (GLP-1) receptor agonists are attractive second-line treatments as they lead to improved glycemic control and weight loss and are associated with a low risk of hypoglycemia [14-16]. Several GLP-1 receptor agonists, including liraglutide $(1.2 \mathrm{mg}$ or $1.8 \mathrm{mg})$, lixisenatide $(10 \mu \mathrm{g}$ or $20 \mu \mathrm{g}$ once daily), exenatide (5 $\mu \mathrm{g}$ or $10 \mu \mathrm{g}$ twice daily) and exenatide once weekly, have already been prescribed to Spanish patients, mostly in specialized diabetes care settings [17].

Both $1.2 \mathrm{mg}$ and $1.8 \mathrm{mg}$ doses of liraglutide have been shown to be cost-effective from a Spanish healthcare payer perspective when compared with the dipeptidyl peptidase-4 (DPP-4) inhibitor sitagliptin in patients who are unresponsive to metformin monotherapy $[18,19]$. In addition, the ability of liraglutide to reduce HbA1c and weight was demonstrated in real-world clinical practice in Spain [20]. However, no studies comparing the cost-effectiveness of liraglutide versus lixisenatide in the Spanish setting have been published to date. The recent publication of the LIRA-LIXI ${ }^{\mathrm{TM}}$ trial has provided high-quality data which allows comparison of the long-term cost-effectiveness of liraglutide $1.8 \mathrm{mg}$ with lixisenatide $20 \mu \mathrm{g}$, both administered once daily, in the Spanish setting for treatment of patients with type 2 diabetes who failed to achieve glycemic control on metformin monotherapy [21].

\section{METHODS}

\section{Model Description}

The IMS CORE Diabetes Model (IMS Health, Basel, Switzerland) was used to evaluate long-term outcomes. The model is a policy analysis tool that allows estimation of clinical 
and cost trajectories of patients with diabetes over longer time horizons than are feasible in clinical trials. It has been successfully validated against published data from clinical and epidemiological studies on initial publication in 2003 and following a series of updates in 2014 [22-24]. The model contains several inter-dependent sub-models to simulate diabetes-related complications (angina, cataract, congestive heart failure, diabetic retinopathy, foot ulcer and amputation, hypoglycemia, ketoacidosis, lactic acidosis, macular edema, myocardial infarction, nephropathy and end-stage renal disease, neuropathy, peripheral vascular disease, stroke and non-specific mortality). Sub-models have a semi-Markov structure and use time, time-in-state and diabetes type-dependent probabilities derived from published sources. While standard Markov models are memory-less, the IMS CORE model uses Monte Carlo simulation with tracker variables to model patient history and to allow for interactions between sub-models.

In line with Spanish and international recommendations on the economic evaluation of health technologies, long-term complications and costs as well as their impact on (quality-adjusted) life expectancy were assessed by projecting outcomes over patient lifetimes [25, 26]. Future costs and benefits were discounted at 3\% annually, as per recommendations for Spain [26].

\section{Simulated Cohort and Treatment Effects}

The LIRA-LIXI ${ }^{\mathrm{TM}}$ trial (NCT01973231) provided the baseline cohort characteristics and treatment effects modeled in the analysis. The trial was a 26-week, open-label study in nine European countries that enrolled 404 adults with type 2 diabetes who had failed to meet glycemic targets on metformin monotherapy [21]. Study participants were randomly allocated in equal numbers to therapy with liraglutide $1.8 \mathrm{mg}$ or therapy with lixisenatide $20 \mu \mathrm{g}$, both to be administered once daily.

At baseline, the cohort had a mean age of 56.2 [standard deviation (SD) 10.3] years and a mean body mass index (BMI) of $34.7 \mathrm{~kg} / \mathrm{m}^{2}$ (SD $6.7 \mathrm{~kg}$ / $\mathrm{m}^{2}$ ), with a mean glycated hemoglobin (HbA1c) of $8.4 \%$ (SD $0.8 \%$ ) and a mean diabetes duration of 6.4 (SD 5.1) years. The LIRA-LIXI ${ }^{\mathrm{TM}}$ trial data did not provide data on smoking and alcohol consumption so these were retrieved from external population data sources for Spain $[27,28]$.

After 26 weeks, liraglutide $1.8 \mathrm{mg}$ was associated with a larger decrease in $\mathrm{HbA} 1 \mathrm{c}$ $(-1.83 \%)$ than lixisenatide $20 \mu \mathrm{g}(-1.21 \%)$, with an HbA1c difference of $-0.62 \% \quad(95 \%$ confidence interval -0.80 to $-0.44 \%$, $p<0.0001$ ) (Table 1). Glycemic targets of HbA1c of $<7.0 \%$ and HbA1c of $\leq 6.5 \%$ were achieved by a statistically significantly larger proportion ( $p<0.0001$ for all targets) of patients receiving liraglutide $1.8 \mathrm{mg}$ compared with patients receiving lixisenatide $20 \mu \mathrm{g}$, but no statistically significant differences between treatments were observed for changes in BMI, lipid profile, blood pressure or the number of hypoglycemic episodes (Table 1). Outcomes at the end of the trial were used in the analysis as first-year treatment effects of initiating GLP-1 receptor agonists. After the first year, the analysis assumed that HbA1c and systolic blood pressure followed natural progression algorithms based on the United Kingdom Prospective Diabetes Study (UKPDS) and that serum lipids followed progression equations based on the Framingham Heart Study. During GLP-1 receptor agonist treatment, BMI was assumed to remain constant before returning to baseline level on treatment intensification.

The simulated cohort of patients received GLP-1 receptor agonists for 3 years. A 3-year period was chosen based on the results of the LEADER trial which reported a mean time of exposure to liraglutide of 3.1 years [29]. After 3 years and for the rest of the simulation, patients were treated with insulin glargine. This assumption is consistent with previous cost-effectiveness analyses of GLP-1 receptor agonists [30]. Both the timing of the switch and the type of insulin switched to were varied in sensitivity analyses.

\section{Costs and Utilities}

Costs were accounted in 2015 Euros (EUR) from the Spanish National Health System payer 
Table 1 Treatment effects applied in the first year of the analysis

\begin{tabular}{lccc}
\hline & $\begin{array}{l}\text { Liraglutide } \mathbf{1 . 8} \mathbf{~ m g} \\
\text { (mean) }\end{array}$ & $\begin{array}{l}\text { Lixisenatide } \mathbf{2 0} \boldsymbol{\mu g} \\
\text { (mean) }\end{array}$ & $\begin{array}{l}\boldsymbol{p} \text { value for } \\
\text { difference }\end{array}$ \\
\hline HbAlc (\%) & -1.83 & -1.21 & 0.0001 \\
Systolic blood pressure (mmHg) & -4.70 & -3.49 & 0.3722 \\
Total cholesterol (mg/dL) & -7.75 & -1.94 & 0.0755 \\
LDL cholesterol (mg/dL) & -4.24 & +1.06 & 0.1140 \\
HDL cholesterol (mg/dL) & +0.93 & +1.86 & 0.4625 \\
Triglycerides (mg/dL) & -34.56 & -20.74 & 0.1044 \\
Body mass index (kg/m ${ }^{2}$ ) & -1.48 & -1.28 & 0.2255 \\
Severe hypoglycemic event rate (events per 100 & 0.00 & 0.00 & - \\
$\quad$ patient-years) & & & \\
Non-severe hypoglycemic event rate (events per 100 & 4.20 & 8.70 & 0.4980 \\
patient-years) & & & \\
\hline
\end{tabular}

$H b A 1 c$ glycated hemoglobin, $H D L$ high density lipoprotein, $L D L$ low density lipoprotein

perspective. Annual treatment costs were based on published wholesale acquisition prices and included the costs of GLP-1 receptor agonists and the needles needed for their injection, of concomitant metformin therapy and of self-monitoring of blood glucose testing, which was assumed to be three tests per week in both arms of the analysis. Costs of treating diabetes-related complications were identified from literature reviews and Spanish databases and were inflated to 2015 prices using the consumer price index for health [31-39]. Diabetes and its complications affect the quality of life, and this was captured by applying published event disutilities in the year when the complication occurred and published state utilities in all subsequent years [40-43]. All values have been used in published cost-effectiveness analyses of liraglutide $[19,44,45]$.

Projection of quality-adjusted life expectancy [measured in quality-adjusted life years (QALYs)] is used widely in cost-effectiveness analyses and is accepted as a useful, relevant metric for decision-makers and payers, although this approach is not without its limitations [46, 47].

\section{Sensitivity Analyses}

A number of sensitivity analyses were conducted as part of this study, in line with published recommendations [26]. The time horizon was reduced to 10 and 20 years to assess the impact of varying the time horizon on health economic outcomes. The impact of discounting was evaluated by conducting analyses with discount rates that varied between 0 and $5 \%$. Key drivers of clinical outcomes were identified by individually setting differences in clinical parameters (e.g. HbA1c, BMI or hypoglycemic event rates) between treatment arms to zero. An additional analysis set all clinical parameters equal to their values in the lixisenatide arm, except for the statistically significant difference in $\mathrm{HbA1c}$ in the liraglutide arm.

Several analyses were performed to evaluate the impact of alternative treatment-switching options as patients treated with GLP-1 receptor agonist therapy will eventually require insulin. First, in both arms treatment was switched to insulin glargine only after 5 years of GLP-1 receptor agonist therapy, which approximated the upper observation time limit in the LEADER 
trial [29]. Second, patients switched to insulin glargine when the HbA1c level exceeded 7.5\%. Third, patients switched to neutral protamine Hagedorn (NPH) insulin instead of insulin glargine after 3 years of GLP-1 receptor agonist therapy.

Over- or underestimation of direct costs of diabetes-related complications might also influence results. Therefore, the analysis was conducted with costs increased and decreased by $10 \%$, respectively. A further sensitivity analysis was performed using an updated version of the IMS CORE Diabetes Model, which was released in 2014 and incorporates data from the UKPDS 82 study. The model proprietors recommend that this version is used only for sensitivity analyses and the previous version is used for the base case [25].

Probabilistic sensitivity analysis (PSA) was performed using a second-order Monte Carlo approach. Transition probabilities (sampled based on regression co-efficients), utilities (beta distributions) direct costs (log-normal distributions), treatment effects (beta distributions) and cohort characteristics (normal distributions) were sampled. One thousand cohorts of 1000 patients were simulated in the PSA and used to generate cost-effectiveness scatterplots and acceptability curves which were used to analyze the probability that a treatment may be cost-effective over a range of willingness to pay thresholds. No fixed willingness to pay threshold exists in Spain but earlier studies have used thresholds of between EUR 20,000 and EUR 30,000 per QALY gained [48, 49].

\section{Compliance with Ethics Guidelines}

This article does not contain any new studies of human or animal subjects performed by any of the authors.

\section{RESULTS}

\section{Base Case Analysis}

Liraglutide $1.8 \mathrm{mg}$ was associated with improved discounted life expectancy (by
0.12 years) and discounted quality-adjusted life expectancy (by 0.13 QALYs) compared with lixisenatide $20 \mu \mathrm{g}$ in patients with type 2 diabetes failing metformin monotherapy (Table 1). Patients receiving liraglutide $1.8 \mathrm{mg}$ benefitted from a reduced cumulative incidence of diabetes-related complications over their lifetimes (Fig. 1). When diabetes-related complications occurred, they occurred, on average, 0.35 years later in patients treated with liraglutide $1.8 \mathrm{mg}$ than in those treated with lixisenatide $20 \mu \mathrm{g}$. A delayed onset was observed for all complications, most notably for neuropathy which occurred, on average, 0.45 years later in patients treated with liraglutide $1.8 \mathrm{mg}$.

Treatment with liraglutide $1.8 \mathrm{mg}$ was associated with higher direct costs over patient lifetimes, with a mean difference of EUR 545 per patient (Fig. 2). Higher treatment costs over the first 3 years of the analysis were responsible for the higher overall costs of liraglutide $1.8 \mathrm{mg}$. Lower costs of treatment of diabetes-related complications, however, partly offset the higher pharmacy costs. Liraglutide $1.8 \mathrm{mg}$ notably reduced costs of treating diabetic foot complications compared with lixisenatide $20 \mu \mathrm{g}$, with mean cost savings of EUR 641 per patient.

Combining clinical and economic results generated incremental cost-effectiveness ratios (ICERs) of EUR 4493 per life-year gained and EUR 4113 per QALY gained for liraglutide $1.8 \mathrm{mg}$ versus lixisenatide $20 \mu \mathrm{g}$ (Table 2 ).

\section{Sensitivity Analyses}

Sensitivity analyses showed that variation in the time horizon, the timing of the switch from GLP-1 receptor agonist treatment to insulin, the use of a $7.5 \%$ HbA1c threshold to trigger the switch to insulin and the difference in HbA1c between the treatment arms had the greatest impact on cost-effectiveness outcomes (Table 3).

When shorter time horizons were used, ICERs increased to EUR 17,130 and EUR 5104 per QALY gained for 10- and 20-year horizons, respectively. Shorter time horizons did not 


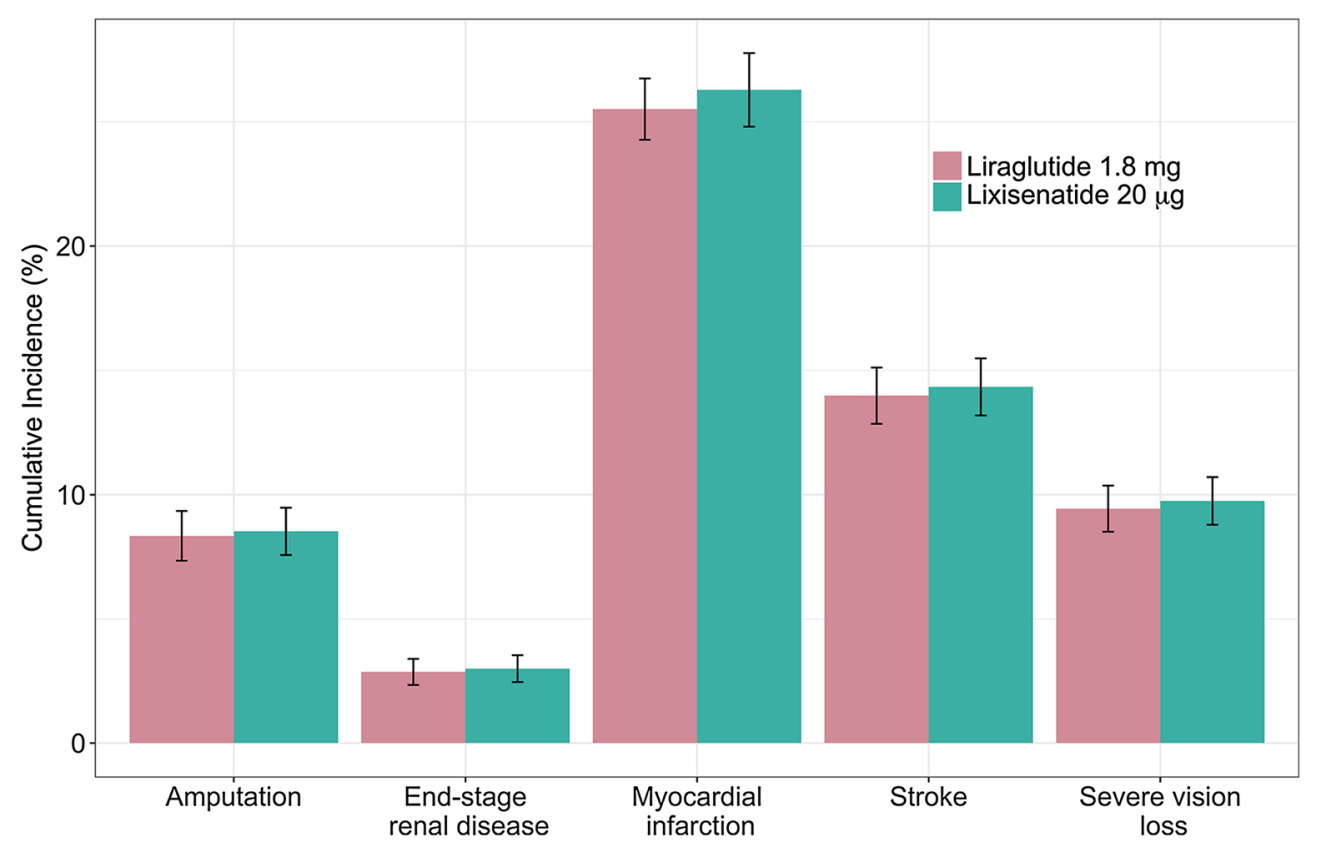

Fig. 1 Comparison of treatment with liraglutide $1.8 \mathrm{mg}$ vs. lixisenatide $20 \mu \mathrm{g}$ in terms of cumulative lifetime incidence of diabetes-related complications. Bars Standard deviations (SD). All differences in incidences between liraglutide $1.8 \mathrm{mg}$ and lixisenatide $20 \mu \mathrm{g}$ were statistically significant at the $5 \%$ level of significance

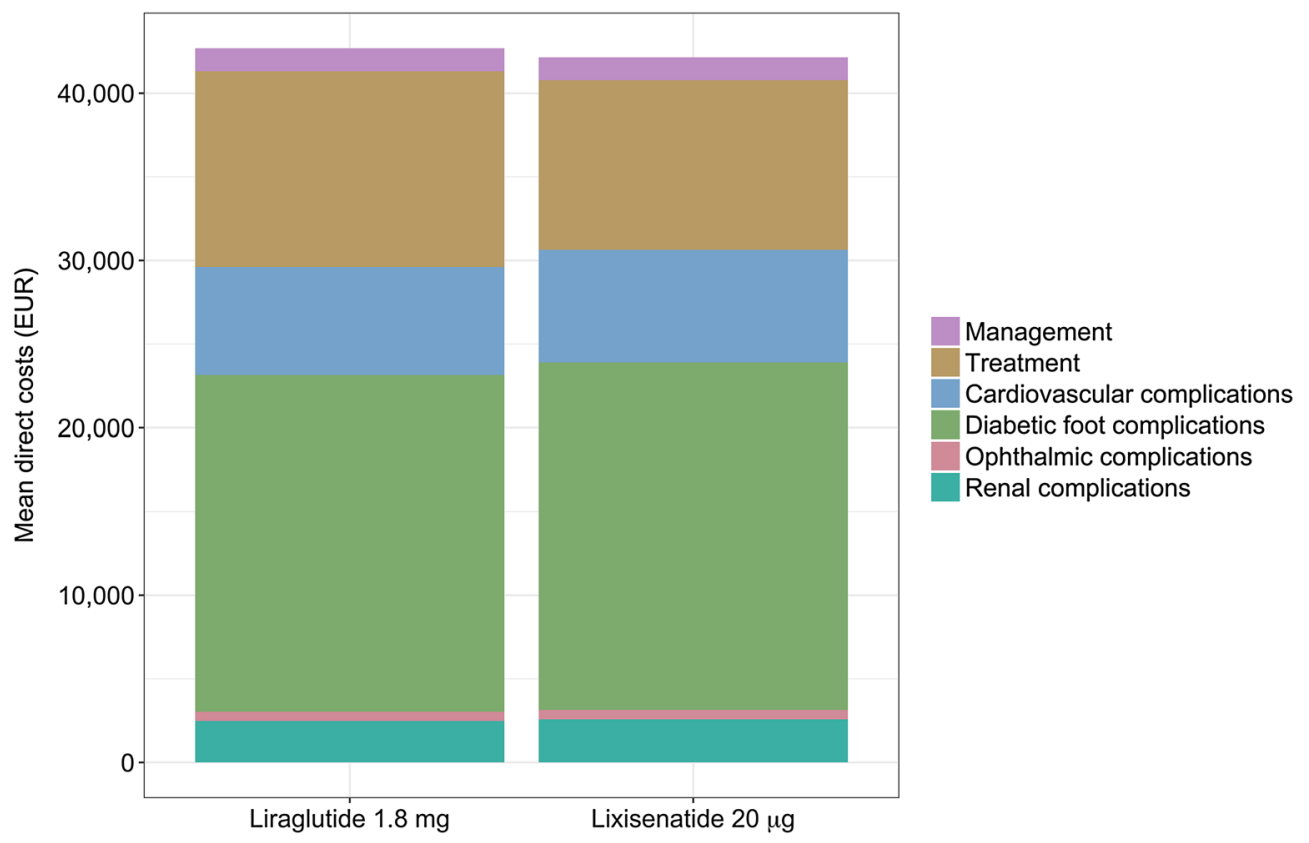

Fig. 2 Direct costs of treatment with liraglutide $1.8 \mathrm{mg}$ versus lixisenatide $20 \mu \mathrm{g}$ over patient lifetimes. EUR 2015 Euros capture fully the long-term clinical benefits of liraglutide $1.8 \mathrm{mg}$, thereby resulting in increased ICERs. The ICER decreased when current and future benefits and costs were

discounted at $0 \%$ per annum. In contrast, the ICER increased when future benefits and costs were discounted more heavily at a discount rate of $5 \%$ annually. 
Table 2 Long-term cost-effectiveness outcomes of treatment with liraglutide $1.8 \mathrm{mg}$ versus lixisenatide $20 \mu \mathrm{g}$

\begin{tabular}{llll}
\hline & Liraglutide $\mathbf{1 . 8} \mathbf{~ m g}$ & Lixisenatide 20 $\mathbf{~ g}$ & Difference \\
\hline Discounted life expectancy (years) & $14.42(0.18)$ & $14.29(0.19)$ & +0.12 \\
Discounted quality-adjusted life expectancy (QALYs) & $9.40(0.12)$ & $9.26(0.13)$ & +0.13 \\
Discounted direct costs (EUR) & $42,689(1125)$ & $42,143(1088)$ & +545 \\
ICER (life expectancy) & EUR 4493 per life year gained & \\
ICER (quality-adjusted life expectancy) & EUR 4113 per QALY gained \\
\hline
\end{tabular}

Values in table are given as the mean with the standard deviation (SD) in parenthesis

EUR 2015 Euros, ICER incremental cost-effectiveness ratio, QALY quality-adjusted life year

Improved $\mathrm{HbA1c}$ in the liraglutide $1.8 \mathrm{mg}$ arm compared with the lixisenatide $20 \mu \mathrm{g}$ arm was the main driver of improved clinical outcomes. Abolishing the difference in HbA1c reduced the difference in quality-adjusted life expectancy to only 0.04 QALYs and increased the ICER to EUR 37,282 per QALY gained. When only the statistically significant difference in HbA1c between treatment arms was retained, with all other between-treatment differences set to zero, the ICER was EUR 6009 per QALY gained.

Switching to insulin glargine after 5 years increased the ICER to EUR 10,549 per QALY gained. The ICER also increased when treatment was switched to insulin glargine asymmetrically after an HbA1c threshold of $7.5 \%$ was exceeded. The threshold was exceeded after 4 years of liraglutide $1.8 \mathrm{mg}$ therapy and 2 years of lixisenatide $20 \mu \mathrm{g}$ therapy. When patients switched to NPH insulin instead of insulin glargine after 3 years, treatment costs in both arms fell and the ICER decreased slightly relative to the base case.

Increasing the costs of diabetes-related complications by $10 \%$ decreased the ICER to EUR 3342 per QALY gained, as the higher number of complications avoided resulted in larger avoided costs in the liraglutide $1.8 \mathrm{mg}$ arm compared with the lixisenatide $20 \mu \mathrm{g}$ arm. Conversely, a $10 \%$ decrease in diabetes-related costs increased the ICER to EUR 4885 per QALY gained.

Using the alternative UKPDS equations decreased the difference in quality-adjusted life expectancy between treatments and reduced the cost offsets of complications avoided with liraglutide $1.8 \mathrm{mg}$ more than those of lixisenatide $20 \mu \mathrm{g}$, resulting in an ICER of EUR 5712 per QALY gained.

The probabilistic sensitivity analysis indicated a $74.2 \%$ probability that liraglutide $1.8 \mathrm{mg}$ would be considered cost-effective versus lixisenatide $20 \mu \mathrm{g}$ at a willingness-to-pay threshold of EUR 20,000 per QALY gained. At a willingness-to-pay threshold of EUR 30,000 per QALY gained, the probability increased to $75.5 \%$ (Fig. 3).

\section{DISCUSSION}

The present analysis showed that patients with type 2 diabetes failing metformin monotherapy were likely to benefit from improved long-term clinical outcomes when treated with liraglutide $1.8 \mathrm{mg}$ compared with lixisenatide $20 \mu \mathrm{g}$. Improved glycemic control with liraglutide $1.8 \mathrm{mg}$ resulted in fewer diabetes-related complications, and improved life expectancy and quality-adjusted life expectancy. While liraglutide $1.8 \mathrm{mg}$ treatment was associated with increased direct costs compared with lixisenatide $20 \mu \mathrm{g}$, lower costs of treating complications partly offset the higher acquisition costs. Combining clinical and economic outcomes yielded an ICER of EUR 4113 per QALY gained for liraglutide $1.8 \mathrm{mg}$ versus lixisenatide $20 \mu \mathrm{g}$. This ICER falls well below the willingness-to-pay 


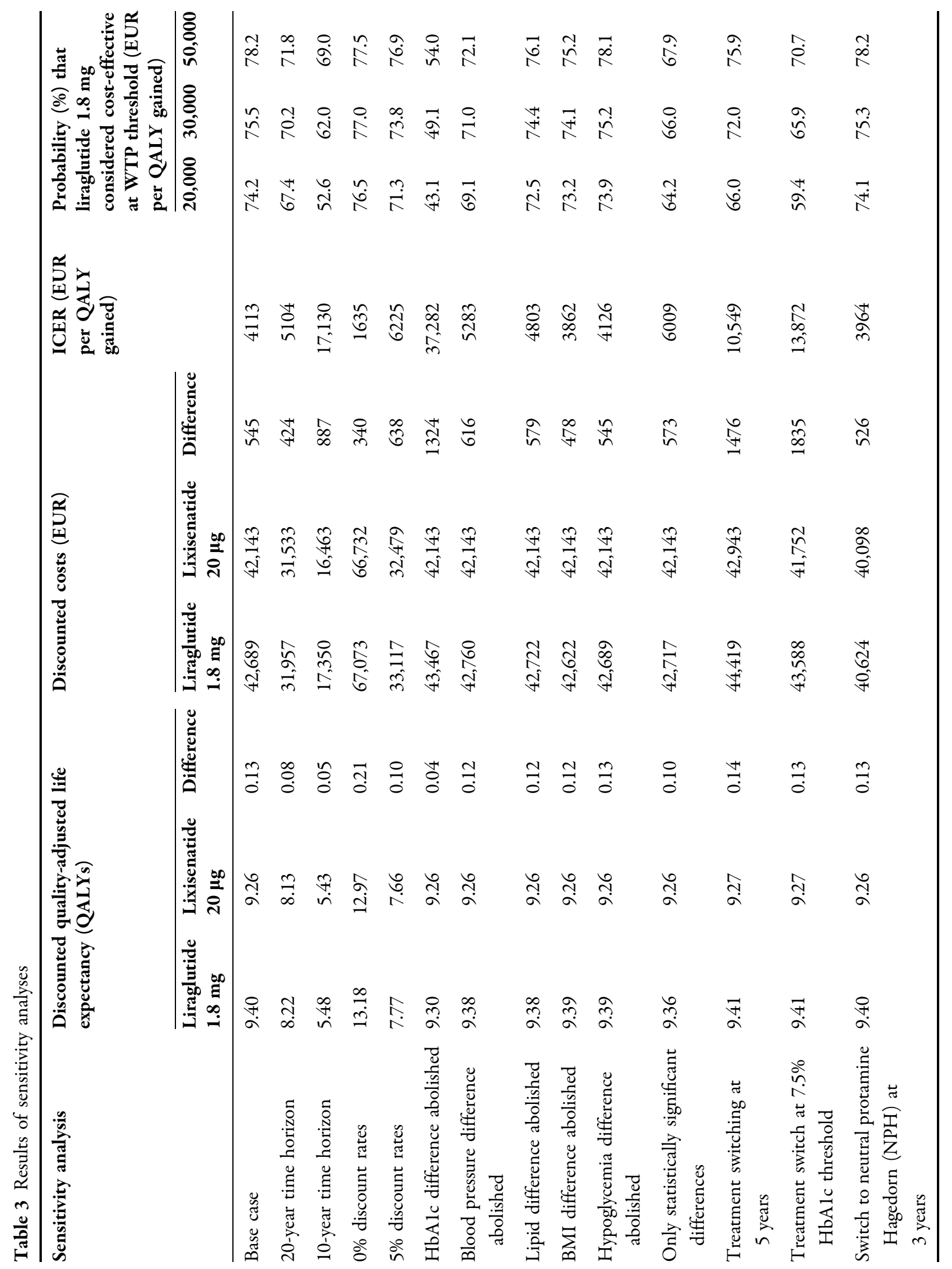




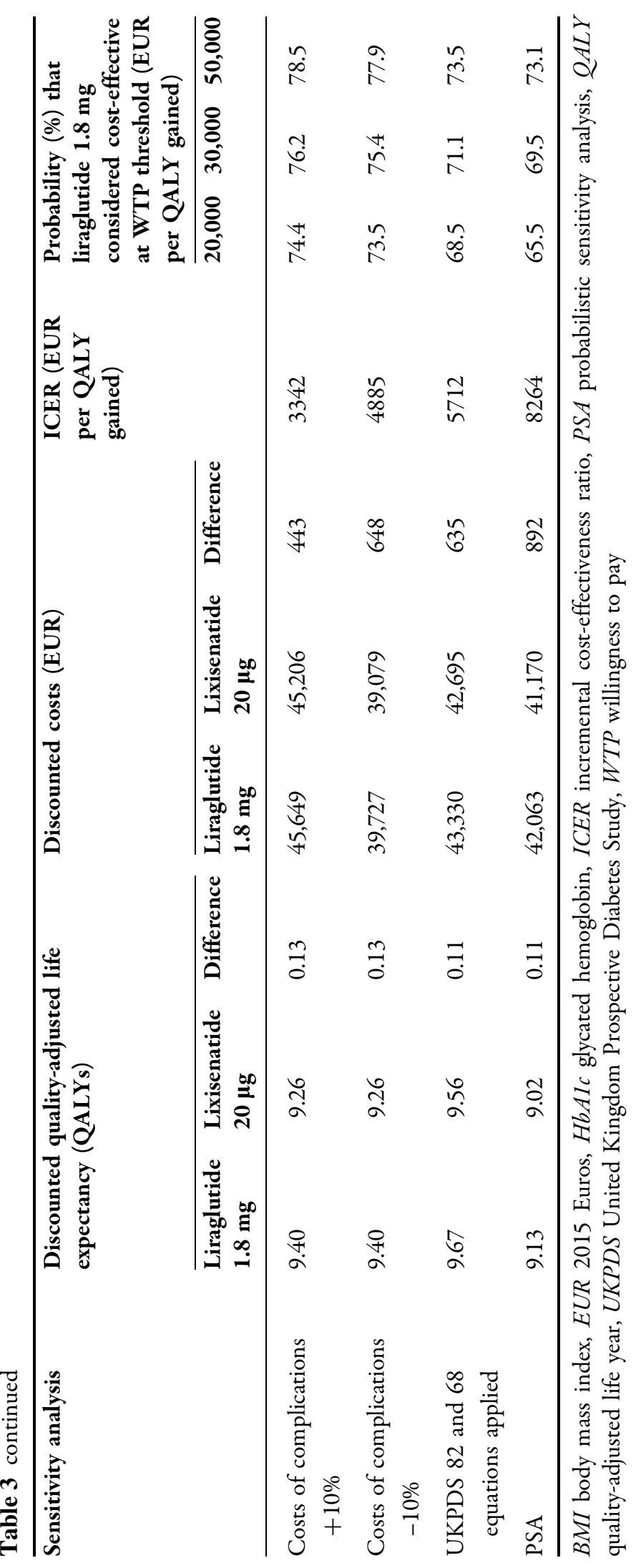




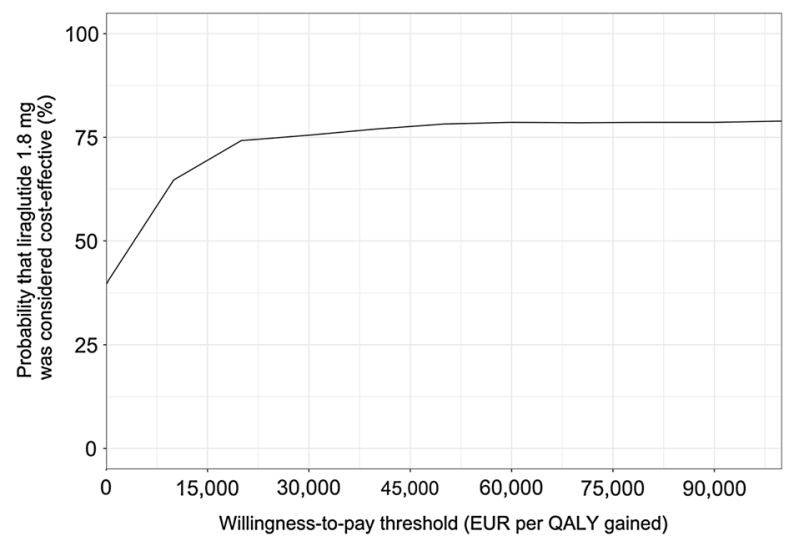

Fig. 3 Cost-effectiveness acceptability curve. Probabilities that liraglutide $1.8 \mathrm{mg}$ was considered to be cost-effective were $74.2,75.5$ and $78.2 \%$ at willingness-to-pay thresholds of EUR 20,000, EUR 30,000 and EUR 50,000 per quality-adjusted life year $(Q A L Y)$ gained, respectively. EUR 2015 Euros

threshold of EUR 20,000 to EUR 30,000 per QALY gained that is commonly referenced in the Spanish setting. From the perspective of a Spanish National Health System payer, liraglutide $1.8 \mathrm{mg}$ is likely to be considered a cost-effective add-on therapy to metformin for Spanish patients with type 2 diabetes.

The improved glycemic control associated with liraglutide $1.8 \mathrm{mg}$ compared with lixisenatide $20 \mu \mathrm{g}$ in the LIRA-LIXI ${ }^{\mathrm{TM}}$ trial was the key driver of the long-term benefit of liraglutide $1.8 \mathrm{mg}$. Sensitivity analyses showed that the ICER would increase to EUR 37,282 per QALY gained if the HbA1c difference between the two treatments were to be abolished. Additional sensitivity analyses indicated that results were robust to changes in modeling assumptions and input parameters, with no ICER higher than EUR 17,130 per QALY gained reported. As the benefits of liraglutide $1.8 \mathrm{mg}$ accrue over patient lifetimes, a long-term perspective was found to be important.

The $1.83 \%$ (20 mmol $/ \mathrm{mol})$ decrease in $\mathrm{HbA1c}$ observed with liraglutide $1.8 \mathrm{mg}$ in the LIRA-LIXI $^{\mathrm{TM}}$ trial was higher than the average decrease of $1.15 \%$ calculated in a meta-analysis of seven clinical trials from the liraglutide clinical trial program [50]. However, the effect of lixisenatide $20 \mu \mathrm{g}$ on HbA1c was also greater than observed previously. The LIRA-LIXI ${ }^{\mathrm{TM}}$ trial identified a reduction in $\mathrm{HbA} 1 \mathrm{c}$ of $1.21 \%$ with lixisenatide $20 \mu \mathrm{g}$, while the lixisenatide trial program identified reductions of between 0.8 and $0.9 \%$ [51]. It is currently unclear why glycemic control improved to a greater extent in both arms of the LIRA-LIXI $^{\mathrm{TM}}$ trial compared with earlier studies.

Multifactorial treatments of type 2 diabetes target both glycemic control and other risk factors for diabetes-related complications, including hypertension or dyslipidemia. Several studies, particularly the Steno-2 and ADDITION trials, have compared the effects of multifactorial and conventional treatment approaches on risk factors and rates of diabetes-related complications [52, 53]. Multifactorial treatment was associated with reduced aortic stiffness over 6.2 years of follow-up, with a decreased risk of modeled cardiovascular disease, decreased risks of all-cause and cardiovascular mortality, autonomic neuropathy, nephropathy and retinopathy, and a median gain of 7.9 life-years over a follow-up of 21.2 years [10, 54-56].

As GLP-1 receptors are present in a number of tissues throughout the body, GLP-1 receptor agonists have numerous physiological effects, including inhibited glucagon release, glucose-dependent stimulation of insulin secretion and delayed gastric emptying, which makes them well suited as a multifactorial treatment for diabetes [14, 15]. Liraglutide was also associated with statistically significant reductions in nephropathy, cardiovascular disease risk and death from any cause compared with placebo treatment in the LEADER trial [29]. A similar trial that compared lixisenatide $20 \mu \mathrm{g}$ with placebo [Evaluation of Lixisenatide in Acute Coronary Syndrome (ELIXA) trial] did not find statistically significant differences between the treatment and control arms for the primary endpoint of death from cardiovascular causes, nonfatal stroke, nonfatal myocardial infarction or unstable angina over a mean follow-up of 25 months [57]. While further trials on the long-term cardiovascular effects of GLP-1 receptor agonists are necessary, the early evidence now available suggests that liraglutide has a protective cardiovascular effect while lixisenatide has a neutral cardiovascular risk profile. The effect of 
exclusion of this potential benefit in the present analysis was likely to be conservative.

Results from randomized controlled trials suggest that liraglutide $1.8 \mathrm{mg}$ is more effective in reaching glycemic targets than other GLP-1 receptor agonists or DPP-4 inhibitors, including exenatide once weekly, exenatide twice daily or sitagliptin [58-60]. In addition, the clinical effectiveness and cost-effectiveness of both liraglutide $1.2 \mathrm{mg}$ and liraglutide $1.8 \mathrm{mg}$, compared with sitagliptin, have been demonstrated in Spain [18-20]. The present analysis suggests that liraglutide $1.8 \mathrm{mg}$ was also cost-effective compared with lixisenatide $20 \mu \mathrm{g}$ in the Spanish setting. These data further suggest that liraglutide $1.8 \mathrm{mg}$, and GLP-1 receptor agonists in general, may well represent clinically and economically valuable treatment options for many patients in Spain $[17,61]$. The present cost-effectiveness study compared two of the treatment options available to Spanish patients, based on recently available, high-quality trial data, to provide timely information for patients, physicians and decision-makers in the Spanish setting. A full cost-effectiveness analysis comparing all treatment options for patients not achieving glycemic control on metformin monotherapy, which was beyond the scope of this study, might be conducted in the future and combine evidence from this and earlier studies.

The present analysis is possibly limited by the use of short-term clinical trial data to project long-term outcomes, a limitation faced by many cost-effectiveness analyses. Using a published and validated diabetes model accepted by reimbursement authorities worldwide likely minimized the effect of using short-term data. However, modeling studies based on short-term data can be a valuable resource to decision-makers in the absence of long-term data.

The open-label design of the LIRA-LIXI ${ }^{\mathrm{TM}}$ trial may be a second limitation, which was unavoidable given the different titration protocols of liraglutide $1.8 \mathrm{mg}$ and lixisenatide $20 \mu \mathrm{g}$. It is conceivable that knowledge about which drug was assigned to a patient affected expectations with regard to medication results, adherence to medication or lifestyle recommendations, as well as reporting or assessment of adverse events. The impact of such biases, if any, is difficult to assess.

A further limitation may be that the LIRA-LIXI $^{\mathrm{TM}}$ trial did not include participants from Spain, possibly limiting the generalizability of trial results to the Spanish setting. While this possibility needs to be acknowledged, it was considered likely that the LIRA-LIXI ${ }^{\mathrm{TM}}$ trial results are generalizable to Spain and, therefore, that the conclusions of the present analysis are valid. The trial interventions were judged to be as feasible, acceptable and able to achieve broad coverage in Spain as they were in the trial countries (including Italy, France and Germany), thereby fulfilling an important set of generalizability criteria [62]. In addition, in the absence of other efficacy data specific to Spain, Spanish health economic guidelines recommend the use of trials with high internal validity, to be combined with cost data specific to the Spanish setting, as was done in this analysis [28]. If efficacy data for Spain become available in the future, the present analysis could be replicated with those new data.

\section{CONCLUSION}

This cost-effectiveness analysis showed that the improved clinical outcomes associated with liraglutide $1.8 \mathrm{mg}$ compared with lixisenatide $20 \mu \mathrm{g}$ are likely to result in improved life expectancy and quality-adjusted life expectancy. Patients treated with liraglutide $1.8 \mathrm{mg}$ benefitted in particular from reduced levels of HbA1c compared with patients treated with lixisenatide $20 \mu \mathrm{g}$. The clinical benefits associated with liraglutide $1.8 \mathrm{mg}$ came at an increased cost for Spanish healthcare payers, as acquisition costs of liraglutide $1.8 \mathrm{mg}$ were higher than for lixisenatide $20 \mu \mathrm{g}$, although the reduced incidence, and therefore treatment costs, of diabetes-related complications partially offset higher acquisition costs. Liraglutide $1.8 \mathrm{mg}$ was associated with an incremental cost-effectiveness ratio of EUR 4113 per QALY gained versus lixisenatide $20 \mu \mathrm{g}$. In the Spanish setting, liraglutide $1.8 \mathrm{mg}$, compared with lixisenatide $20 \mu \mathrm{g}$, is likely to be considered a cost-effective add-on to metformin in patients 
with type 2 diabetes who had not achieved glycemic control targets on metformin monotherapy.

\section{ACKNOWLEDGEMENTS}

Sponsorship and article processing charges for this study were funded by Novo Nordisk A/S, Søborg, Denmark. All named authors meet the International Committee of Medical Journal Editors (ICMJE) criteria for authorship for this manuscript, take responsibility for the integrity of the work as a whole and have given final approval to the version to be published. All authors had full access to all of the data in this study and take complete responsibility for the integrity of the data and accuracy of the data analysis.

Disclosures. P. Mezquita-Raya is a scientific collaborator with Novo Nordisk and has participated in advisory boards and clinical trials. A. Ramírez de Arellano is an employee of Novo Nordisk. N. Kragh is an employee of Novo Nordisk. G. Vega-Hernandez is an employee of Novo Nordisk. J. Pöhlmann is an employee of Ossian Health Economics and Communications, which received a consulting fee from Novo Nordisk to support the study. W. Valentine is an employee of Ossian Health Economics and Communications, which received a consulting fee from Novo Nordisk to support the study. B. Hunt is an employee of Ossian Health Economics and Communications, which received a consulting fee from Novo Nordisk to support the study.

Compliance with Ethics Guidelines. This article does not contain any new studies of human or animal subjects performed by any of the authors.

Data Availability. The datasets generated during and/or analyzed during the current study are available from the corresponding author on reasonable request.
Open Access. This article is distributed under the terms of the Creative Commons Attribution-NonCommercial 4.0 International License (http://creativecommons.org/licenses/ by-nc/4.0/), which permits any noncommercial use, distribution, and reproduction in any medium, provided you give appropriate credit to the original author(s) and the source, provide a link to the Creative Commons license, and indicate if changes were made.

\section{REFERENCES}

1. International Diabetes Federation. IDF Diabetes Atlas. 7th ed. Brussels: International Diabetes Federation; 2015.

2. GBD 2015 DALYs, HALE Collaborators. Global, regional, and national disability-adjusted life-years (DALYs) for 315 diseases and injuries and healthy life expectancy (HALE), 1990-2015: a systematic analysis for the Global Burden of Disease Study 2015. Lancet. 2016;388:1603-58.

3. Alonso-Morán E, Orueta JF, Fraile Esteban JI, et al. The prevalence of diabetes-related complications and multimorbidity in the population with type 2 diabetes mellitus in the Basque Country. BMC Public Health. 2014;14:1059.

4. Gómez-Huelgas R, Guijarro-Merino R, Zapatero A, et al. The frequency and impact of hypoglycemia among hospitalized patients with diabetes: a population-based study. J Diabetes Complic. 2015;29:1050-5.

5. Lopez-de-Andres A, Carrasco-Garrido P, Esteban-Hernandez J, Gil-de-Miguel A, Jiménez-García R. Characteristics and hospitalization costs of patients with diabetes in Spain. Diabetes Res Clin Pract. 2010;89:e2-4.

6. Lopez-Bastida J, Boronat M, Moreno JO, Schurer W. Costs, outcomes and challenges for diabetes care in Spain. Global Health. 2013;9:17.

7. Mata-Cases M, Casajuana M, Franch-Nadal J, et al. Direct medical costs attributable to type 2 diabetes mellitus: a population-based study in Catalonia, Spain. Eur J Health Econ. 2016;17:1001-10.

8. Gæde P, Lund-Andersen H, Parving HH, Pedersen O. Effect of a multifactorial intervention on mortality in type 2 diabetes. N Engl J Med. 2008;358:580-91. 
9. Stratton IM, Adler AI, Neil HA, et al. Association of glycaemia with macrovascular and microvascular complications of type 2 diabetes (UKPDS 35): prospective observational study. BMJ. 2000;321:405-12.

10. Webb DR, Khunti K, Gray LJ, et al. Intensive multifactorial intervention improves modelled coronary heart disease risk in screen-detected type 2 diabetes mellitus: a cluster randomized controlled trial. Diabet Med. 2012;29:531-40.

11. Torre EM, Tejedor FJL, Menéndez SA, et al. Recomendaciones para el tratamiento farmacológico de la hiperglucemia en la diabetes tipo 2. Aten Primaria. 2011;43:202.e1-9.

12. Miñambres I, Mediavilla JJ, Sarroca J, Pérez A. Meeting individualized glycemic targets in primary care patients with type 2 diabetes in Spain. BMC Endocr Disord. 2016;16:10.

13. Mata-Cases M, Franch-Nadal J, Real J, Mauricio D. Glycaemic control and antidiabetic treatment trends in primary care centres in patients with type 2 diabetes mellitus during 2007-2013 in Catalonia: a population-based study. BMJ Open. 2016;6:e012463.

14. Prasad-Reddy L, Isaacs D. A clinical review of GLP-1 receptor agonists: efficacy and safety in diabetes and beyond. Drugs Context. 2015;4:212283.

15. Samson SL, Garber AJ. A plethora of GLP-1 agonists: decisions about what to use and when. Curr Diab Rep. 2016;16:120.

16. Samson SL, Garber AJ. GLP-1R agonist therapy for diabetes: benefits and potential risks. Curr Opin Endocrinol Diabetes Obes. 2013;20:87-97.

17. Conget I, Mauricio D, Ortega R, Detournay B, CHADIG Study investigators. Characteristics of patients with type 2 diabetes mellitus newly treated with GLP-1 receptor agonists (CHADIG Study): a cross-sectional multicentre study in Spain. BMJ Open. 2016;6:e010197.

18. Mezquita-Raya P, Pérez A, Ramírez de Arellano A, Briones T, Hunt B, Valentine WJ. Incretin therapy for type 2 diabetes in Spain: a cost-effectiveness analysis of liraglutide versus sitagliptin. Diabetes Ther. 2013;4:417-30.

19. Pérez A, Mezquita-Raya P, de Arellano AR, Briones $\mathrm{T}$, Hunt B, Valentine WJ. Cost-effectiveness analysis of incretin therapy for type 2 diabetes in Spain: $1.8 \mathrm{mg}$ liraglutide versus sitagliptin. Diabetes Ther. 2015;6:61-74.

20. Mezquita-Raya P, Reyes-Garcia R, Moreno-Perez O, et al. Clinical effects of liraglutide in a real-world setting in Spain: eDiabetes-Monitor SEEN Diabetes Mellitus Working Group study. Diabetes Ther. 2015;6:173-85.

21. Nauck M, Rizzo M, Johnson A, Bosch-Traberg H, Madsen J, Cariou B. Once-daily liraglutide versus lixisenatide as add-on to metformin in type 2 diabetes: a 26-week randomized controlled clinical trial. Diabetes Care. 2016;39:1501-9.

22. Palmer AJ, Roze S, Valentine WJ, et al. The CORE Diabetes Model: projecting long-term clinical outcomes, costs and cost-effectiveness of interventions in diabetes mellitus (types 1 and 2) to support clinical and reimbursement decision-making. Curr Med Res Opin. 2004;20:S5-26.

23. Palmer AJ, Roze S, Valentine WJ, et al. Validation of the CORE Diabetes Model against epidemiological and clinical studies. Curr Med Res Opin. 2004;20:S27-40.

24. McEwan P, Foos V, Palmer JL, Lamotte M, Lloyd A, Grant D. Validation of the IMS CORE Diabetes Model. Value Health. 2014;17:714-24.

25. American Diabetes Association Consensus Panel. Guidelines for computer modeling of diabetes and its complications. Diabetes Care. 2004;27:2262-5.

26. López-Bastida J, Oliva J, Antoñanzas F, et al. Spanish recommendations on economic evaluation of health technologies. Eur J Health Econ. 2010;11:513-20.

27. Forey B, Hamling J, Hamling J, Lee P. International smoking statistics web edition: a collection of worldwide historical data-Spain (Internet, cited 2011 Oct 7). http://www.pnlee.co.uk/Downloads/ ISS/ISS-Spain_111007.pdf. Accessed 26 Oct 2016.

28. World Health Organization. Management of substance abuse: country profiles 2014-Spain. Geneva: World Health Organization; 2014.

29. Marso SP, Daniels GH, Brown-Frandsen K, et al. Liraglutide and cardiovascular outcomes in type 2 diabetes. N Engl J Med. 2016;375:311-22.

30. National Institute for Health and Care Excellence (NICE). Exenatide prolonged-release suspension for injection in combination with oral antidiabetic therapy for the treatment of type 2 diabetes. Technology appraisal guidance TA248. London: National Institute for Health and Care Excellence; 2014.

31. Consejo General de Colegios Oficiales de Farmacéuticos. Bot PLUS Web 2.0 (Internet, cited 2013) https://botplusweb.portalfarma.com/botplus. aspx\#. Accessed 26 Oct 2016. 
32. Collegi de Metges de Barcelona. Nomenclator COMB 2014 (Internet, cited 2014). http://www. comb.cat/cat/professional/asselliure/docs/nomencl ator2014.xls. Accessed 26 Oct 2016.

33. Antoñanzas F, Brenes F, Molero JM, et al. Cost-effectiveness of the combination therapy of dutasteride and tamsulosin in the treatment of benign prostatic hyperlasia in Spain. Actas Urol Esp. 2011;35:65-71.

34. Oblikue. Base de datos de costes sanitarios españoles: eSalud (Internet, cited 2007). http:// www.oblikue.com/bddcostes/. Accessed 26 Oct 2016.

35. Osakidetza-Servicio Vasco de Salud. No title (Internet, cited 2013). http://www.osakidetza.euskadi.eus/r85ghhome00/es/. Accessed 26 Oct 2016.

36. Instituto Nacional de Estadística. Indice de precios de consumo base 2011: medias anuales (Internet, cited 2016). http://www.ine.es/jaxiT3/Datos. htm?t=10305. Accessed 27 Oct 2016.

37. Ministerio de Sanidad, Servicious sociales e Igualdad. Norma de referencia: Norma Ministerio APv27.0 (Internet, cited 2010). https://www.msssi. gob.es/estadEstudios/estadisticas/docs/SNS2011_PESOS COSTES_AP27_DEF.pdf. Accessed 27 Oct 2016.

38. Beaudet A, Grabbi E, Maurel F, Ramos M, Lebioda A. Review of cost of diabetes complications in four European countries. Value Health. 2013;16:A443-4.

39. Villa G, Rodríguez-Carmona A, Fernández-Ortiz L, et al. Cost analysis of the Spanish renal replacement therapy programme. Nephrol Dial Transplant. 2011;26:3709-14.

40. Clarke P, Gray A, Holman R. Estimating utility values for health states of type 2 diabetic patients using the EQ-5D (UKPDS 62). Med Decis Making. 2002;22:340-9.

41. Bagust A, Beale S. Modelling EuroQol health-related utility values for diabetic complications from CODE-2 data. Health Econ. 2005;14:217-30.

42. Currie CJ, Morgan CL, Poole CD, Sharplin P, Lammert M, McEwan P. Multivariate models of health-related utility and the fear of hypoglycaemia in people with diabetes. Curr Med Res Opin. 2006;22:1523-34.

43. Tengs TO, Wallace A. One thousand health-related quality-of-life estimates. Med Care. 2000;38:583-637.

44. Davies MJ, Chubb BD, Smith IC, Valentine WJ. Cost-utility analysis of liraglutide compared with sulphonylurea or sitagliptin, all as add-on to metformin monotherapy in Type 2 diabetes mellitus. Diabet Med. 2012;29:313-20.

45. Roussel R, Martinez L, Vandebrouck T, et al. Evaluation of the long-term cost-effectiveness of liraglutide therapy for patients with type 2 diabetes in France. J Med Econ. 2016;19:121-34.

46. Kind P, Lafata JE, Matuszewski K, Raisch D. The use of QALYs in clinical and patient decision-making: issues and prospects. Value Health. 2009;12:S27-30.

47. Whitehead SJ, Ali S. Health outcomes in economic evaluation: the QALY and utilities. Br Med Bull. 2010;96:5-21.

48. Sacristán JA, Oliva J, Del Llano J, Prieto L, Pinto JL. What is an efficient health technology in Spain? Gac Sanit. 2002;16:334-43.

49. Rodriguez JM, Paz S, Lizan L, Gonzalez P. The use of quality-adjusted life-years in the economic evaluation of health technologies in Spain: a review of the 1990-2009 literature. Value Health. 2011;14:458-64.

50. Zinman B, Schmidt WE, Moses A, Lund N, Gough S. Achieving a clinically relevant composite outcome of an HbA1c of $<7 \%$ without weight gain or hypoglycaemia in type 2 diabetes: a meta-analysis of the liraglutide clinical trial programme. Diabetes Obes Metab. 2012;14:77-82.

51. Bain SC. The clinical development program of lixisenatide: a once-daily glucagon-like peptide-1 receptor agonist. Diabetes Ther. 2014;5:367-83.

52. Gæde P, Vedel P, Larsen N, Jensen GV, Parving HH, Pedersen O. Multifactorial intervention and cardiovascular disease in patients with type 2 diabetes. N Engl J Med. 2003;348:383-93.

53. Lauritzen T, Griffin S, Borch-Johnsen K, et al. The ADDITION study: proposed trial of the cost-effectiveness of an intensive multifactorial intervention on morbidity and mortality among people with Type 2 diabetes detected by screening. Int J Obes Relat Metab Disord. 2000;24:S6-11.

54. Johansen NB, Charles M, Vistisen D, et al. Effect of intensive multifactorial treatment compared with routine care on aortic stiffness and central blood pressure among individuals with screen-detected type 2 diabetes: the ADDITION-Denmark study. Diabetes Care. 2012;35:2207-14.

55. Black JA, Sharp SJ, Wareham NJ, et al. Does early intensive multifactorial therapy reduce modelled cardiovascular risk in individuals with screen-detected diabetes? Results from the ADDITION-Europe cluster randomized trial. Diabet Med. 2014;31:647-56. 
56. Gæde P, Oellgaard J, Carstensen B, et al. Years of life gained by multifactorial intervention in patients with type 2 diabetes mellitus and microalbuminuria: 21 years follow-up on the Steno-2 randomised trial. Diabetologia. 2016;59:2298-307.

57. Pfeffer MA, Claggett B, Diaz R, et al. Lixisenatide in patients with type 2 diabetes and acute coronary syndrome. N Engl J Med. 2015;373:2247-57.

58. Buse JB, Nauck M, Forst $T$, et al. Exenatide once weekly versus liraglutide once daily in patients with type 2 diabetes (DURATION-6): a randomised, open-label study. Lancet. 2013;381:117-24.

59. Buse JB, Rosenstock J, Sesti G, et al. Liraglutide once a day versus exenatide twice a day for type 2 diabetes: a 26-week randomised, parallel-group, multinational, open-label trial (LEAD-6). Lancet. 2009;374:39-47.

60. Pratley RE, Nauck M, Bailey T, et al. Liraglutide versus sitagliptin for patients with type 2 diabetes who did not have adequate glycaemic control with metformin: a 26-week, randomised, parallel-group, open-label trial. Lancet. 2010;375:1447-56.

61. Nadal JF, Gutiérrez PC. Type 2 diabetes mellitus and cardiovascular risk factors: is comprehensive treatment required? Med Clin. 2013;141:7-13.

62. Bonell C, Oakley A, Hargreaves J, Strange V, Rees R. Assessment of generalisability in trials of health interventions: suggested framework and systematic review. BMJ. 2006;333(7563):346-9. 